\title{
Impact of Concrete-Pictorial-Abstract Approach with Collaborative Lesson Research on Year Four Pupils' Proficiency in Perimeter
}

\author{
Mohd Shafian Shafiee and Chew Cheng Meng* \\ School of Educational Studies, Universiti Sains Malaysia, 11800 Penang, Malaysia
}

\begin{abstract}
The purpose of this study was to determine whether the concrete-pictorial-abstract (CPA) approach developed based on the Collaborative Lesson Research (CLR) cycles can positively impact Year Four pupils' proficiency in perimeter. Counterbalanced design was used with pre- and post-test in every CLR cycle. The participants involved were three groups of pupils totaling 115 pupils and a group of three teachers. The sampling used was cluster random sampling. A paired-samples t test was used to determine whether there is a significant difference between the pre- and post-test for each CLR cycle while a one-way ANOVA test was used to analyze if there is an increase in proficiency from the first, second and third CLR cycles. The results indicated that there was an increase in the mean post-test scores compared to the mean of pre-test scores and the mean difference between the first, second and third CLR cycles. In conclusion, the CLR cycle carried out helped teachers in developing better teaching plans based on the CPA approach as well as enhancing pupils' proficiency in the perimeter.
\end{abstract}

Keywords: Concrete-picture-abstract approach, collaborative lesson research, ten-year-old pupils' proficiency in perimeter

ARTICLE INFO

Article history:

Received: 26 April 2021

Accepted: 07 October 2021

Published: 03 December 2021

DOI: https://doi.org/10.47836/pjssh.29.4.11

$\overline{\text { E-mail addresses: }}$

shafian@outlook.my (Mohd Shafian Shafiee)

cmchew@usm.my (Chew Cheng Meng)

* Corresponding author

\section{INTRODUCTION}

Perimeter is a topic that needs to be studied by pupils in primary and secondary schools in Malaysia. An introduction to perimeter begins with recognizing two-dimensional and three-dimensional shapes before being introduced to the meaning of perimeter. Learning perimeter can be considered something difficult to understand, especially 
for primary school pupils. Machaba (2016) stated that among the problems faced by pupils is a lack of understanding of the concept of perimeter and failure to use the correct formula while solving perimeter questions. Various problems are also faced by teachers, especially when teaching in the classroom.

To solve the problems pupils and teachers face in learning and teaching perimeter, CLR is recommended because it has organized steps and is an improvement of the Lesson Study. For example, Sutherland et al. (2020) stated that if pupils fail to understand measurement vocabulary, pupils will have difficulty engaging in measurement activities (e.g., measuring the height and width of objects), do not understand teacher instructions (e.g., estimating whiteboard length in meters), and use the correct procedural strategy to measure (for example, measuring from the starting point to the endpoint). Through the CLR, pupils symbol problems and difficulties in understanding and measuring geometry can be examined and improved using an appropriate teaching approach in the classroom.

Lesson Study has been practiced in Japan for a long time ago because of its effectiveness in improving the teachers' teaching and learning methods in the classrooms based on studies conducted (Fernandez \& Yoshida, 2004; Lewis, 2002). Fernandez and Yoshida (2004) describe six basic steps of conducting a Lesson Study, namely: (a) designing a lesson plan collaboratively, (b) making real observations in the classroom when the daily lesson plan is implemented, (c) discussing the lesson plan that has been run in the next class to reflect on it, d) review the lesson plan based on observations and reflections made with group members, (e) re-teach the revised lesson plan, and (f) discuss again the lesson plan which has been implemented further by sharing.

The benefits of Lesson Study practices have been shown by international studies (e.g., Akiba et al., 2019) and local studies (e.g. Aini \& Zanaton, 2018; Lim et al., 2018). Several recent studies related to CLR have been conducted in America by Takahashi and McDougal (2018) and in Qatar by Watanabe et al. (2019). Watanabe et al. (2019) conducted CLR in Qatar through problem-solving with the improvements that have been mentioned in Takahashi and McDougal (2016) as well as Takahashi and McDougal (2018). Watanabe et al. (2019) conducted a professional development project to expand and enhance the mathematics teaching capacity of primary school teachers and preparation in Qatar using CLR. Takahashi and McDougal (2019) discussed the results of Takahashi and McDougal (2018) as well as Watanabe et al. (2019) in relation to the results obtained after the CLR had been implemented along with the steps that need to be taken to improve its effectiveness.

The significance of the study is that CLR, CPA approach, and proficiency have a wide range of interest to pupils and teachers indirectly. CPA approach, for example, can be used as one of the teaching methods in the classroom if appropriate, while the CLR can enhance the professionalism of teachers. The CPA approach through the CLR setup 
can provide ideas to teachers in finding better teaching methods. The CLR can also improve teachers' teaching techniques and pupils' performance in the targeted subjects. In addition, proficiency can be used as a guide in assessing pupils' performance and achievement in the classroom (Takahashi \& McDougal, 2016, 2019).

\section{Collaborative Lesson Research (CLR)}

CLR is an updated version of Lesson Study practice introduced by Takahashi and McDougal (2016). Takahashi and McDougal (2016) have improved Lesson Study practices by introducing Collaborative Lesson Research (CLR) to increase efficiency to the maximum level by revising the steps that have been introduced in Lesson Study. CLR was selected in the research based on modifications made by Takahashi and McDougal (2016) in the Lesson Study steps. Among the changes implemented was to define clearer goals in the first step before designing a daily lesson plan and revising it. The main goal of the study was to improve pupils' proficiency in perimeter through the CLR. The six steps in CLR aimed to build on and transform the existing CPA approach to a more effective teaching approach. The goals, teaching approach, and teaching aids were determined collaboratively through discussions among the members of the CLR group. The components in the CLR are as follows (Takahashi \& McDougal, 2016):

a. The purpose of the research is clear: Before starting the research, the purpose should be clearly stated in terms of the problem encountered.
The content should also be accurate, and specific and not general.

b. Kyouzai Kenkyuu: Kyouzai Kenkyuu refers to the comprehensive study of the literature on the topic or problem encountered.

c. Written research proposal: The written proposal should be clear and relevant to the content due to Kyouzai Kenkyuu and help build ideas about the research to be conducted.

d. Actual teaching in the classroom and discussion: Teaching in the classroom is direct and requires views and comments from all the participants involved in the research.

e. Knowledgeable outside observers: Outside observers who can provide independent comments and suggestions before and after the lesson is conducted.

f. Sharing results together: Sharing information obtained from the research is important in ensuring that the effectiveness of CLR can be achieved.

The six components mentioned above are important in ensuring that the main goals are achieved when CLR is carried out in solving the problems encountered, especially in the topic of the perimeter. Takahashi and McDougal (2016) assert that these six components are necessary for ensuring the effective implementation of the CLR cycle. Furthermore, the latest studies (Takahashi \& McDougal, 2018, 
2019; Watanabe et al., 2019) in CLR showed positive feedback and impact for the teachers and students.

\section{CPA Approach}

The CPA approach comprises three main steps, namely concrete, pictorial, and abstract, which adapt to Bruner's (1966) three modes of representation. Bruner (1966) states that the three modes of representation are enactive, iconic, and symbolic. Enactive representation means learning is through motor responses or actions, iconic representation means learning is through the perception of images or pictures, while symbolic representation means learning is through symbols or notations (Bruner, 1964). Thus, through the three modes of representation described by Bruner (1966), the CPA approach has been represented by the concrete step in enactive representation, the pictorial step in iconic representation, and the abstract step in symbolic representation.

Many studies (e.g., Bouck et al., 2018; Flores, 2018; Flores \& Hinton, 2019; Flores et al., 2019; Hinton \& Flores, 2019; Isip, 2018; Purwadi et al., 2019; Salingay \& Tan, 2018) had shown significant improvement in student's performance in mathematics when the CPA approach was implemented in the classrooms. Most teachers only use existing tools in the classroom without realizing whether the tools can be used meaningfully or not to pupils. The construction of lesson plans and tools for the CPA approach was through discussion between CLR group members. Each group member in the CLR will detect deficiencies in the methods and tools available at each live teaching session that occurs before making changes in the next session. The CPA approach also allows for the construction of teaching aids that are more concrete and meaningful. The difficulties when learning geometry and measurement can be reduced if teachers' and pupils' correct use of teaching aids occurs during teaching and learning. Zhang (2021) stated that pupils who face problems in geometry are pupils who have low achievement in other domains of mathematics. Zhang's (2021) findings indicate that learning or difficulty in basic geometry is due to the absence of a visual representation. The absence of a visual representation is one of the things attempted in the CPA approach through the concrete and pictorial steps.

\section{Mathematical Proficiency}

The National Research Council (2001) defines the Mathematical Proficiency framework proposed by Kilpatrick et al. (2001) as consisting of five interrelated components, namely: (i) Conceptual understanding - the understanding of the concept of operations and mathematical relationships; (ii) Procedural fluency - the skills in carrying out procedures flexibly, accurately, efficiently and appropriately; (iii) Strategic competence - the ability to design, represent and solve mathematical problems; (iv) Adaptive reasoning - the ability for logical thinking, reflection, explanation and justification; and (v) Productive disposition - the tendency to 
view mathematics as meaningful, useful and worthwhile, coupled with a belief in perseverance and self-efficacy. Based on the framework, pupils who are proficient in the perimeter have acquired all the five components in the perimeter of squares, rectangles, and triangles.

\section{Perimeter}

The perimeter has been defined as a measure of the length of a boundary within an area (Ma, 1999), while Danielson (2005) states that a perimeter is the length of a boundary within range. Previous studies (e.g., Machaba, 2016; Van de Walle et al., 2014) reported that most pupils and adults had the misconception that figures with the same perimeter must have the same area. Van de Walle et al. (2014) suggest that it is perhaps because both area and perimeter involve measurements, or because pupils are taught formulae for both concepts at about the same time, that they tend to get the formulae confused.

\section{Statement of the Problem}

However, based on the above literature review, there is yet a study to date that examines the impact of the CPA approach with CLR on Year Four pupils' proficiency in perimeter. Hence, this study aimed to fill the research gap by examining whether the CPA approach developed based on the CLR cycle can have a positive impact on Year Four pupils' proficiency in the perimeter.

\section{Theoretical and Conceptual Framework}

The theoretical framework underpinning this study consists of Bruner's (1966) three modes of representation, Takahashi and McDougal's (2016) CLR and Kilpatrick et al.'s (2001) Mathematical Proficiency framework for the CPA approach, 3 CLR cycles, and proficiency in perimeter, respectively. Based on the study's aims, the study's conceptual framework in Figure 1 shows whether the CPA approach developed based on the 3 CLR cycles could positively impact Year Four pupils' proficiency in the perimeter of squares, rectangles, and triangles.

\section{METHODOLOGY}

\section{Research Design}

Based on the study's aims, the research design of this study was a counterbalanced experimental design so that all treatments for each group of participants involved

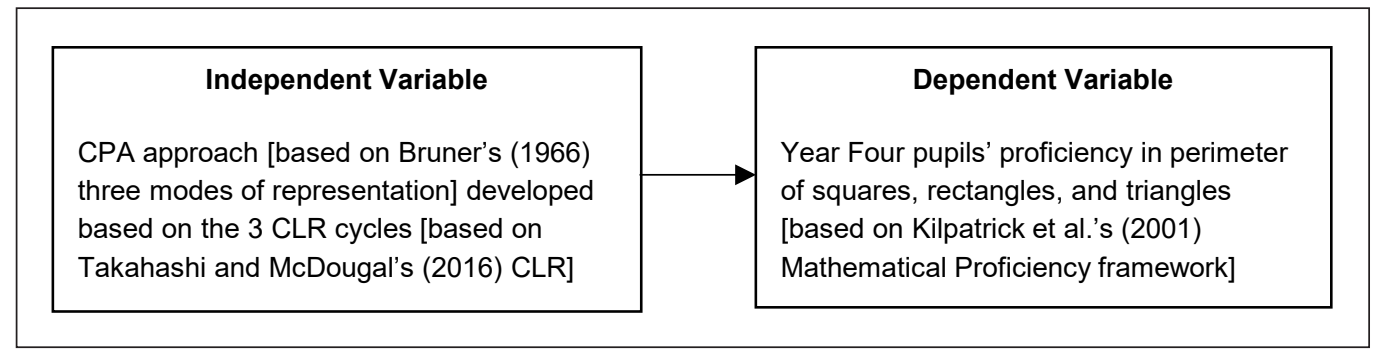

Figure 1. Theoretical and conceptual framework of the study 
are tested equally. The design consisted of three different groups of participants with three treatments applied to each group. Each group went through the pre-test, followed by the treatment, and ended with the post-test. The analysis was conducted quantitatively through pre-and post-tests to determine any significant difference in the pupils' proficiency in perimeter among the three groups. The research design is as shown in Table 1.

\section{Variables}

The independent variable for this study was the CPA approach with CLR. Effect or outcome (i.e., changes or differences in behavior or characteristics) is the dependent variable (Gay et al., 2011). The dependent variable was proficiency in the perimeter. The dependent variable has a relation with the independent variable. The characteristics of a dependent variable depend on or are influenced by the independent variable (Creswell, 2005).

\section{Population and Sampling}

The accessible population of this study consisted of all Year Four pupils studying at

Table 1

Research Design

\begin{tabular}{lccccccccc}
\hline Topic & \multicolumn{3}{c}{ Square } & \multicolumn{3}{c}{ Rectangle } & \multicolumn{3}{c}{ Triangle } \\
\hline Cycle & C1 & C2 & C3 & C1 & C2 & C3 & C1 & C2 & C3 \\
Lesson Plan & & First & & & Second & & & Third & \\
Group Rotation & G1 & G2 & G3 & G2 & G3 & G1 & G3 & G1 & G2 \\
Teacher & T1 & T2 & T3 & T2 & T3 & T1 & T3 & T1 & T2 \\
\hline
\end{tabular}

Notes: $\mathrm{C} 1$ = First Cycle; $\mathrm{C} 2=$ Second Cycle; $\mathrm{C} 3=$ Third Cycle

G1 = Group One; G2 = Group Two; G3 = Group Three

$\mathrm{T} 1$ = Group One Teacher; T2 = Group Two Teacher; T3 = Group Three Teacher of Penang, Malaysia. Cluster random sampling was used to select one school from the study population to obtain an intact group of population members with similar characteristics as the study sample (Gay et al., 2011). Sampling errors can be avoided because the sample is large, and the study's cost is effective. In addition, research with a higher sample size may yield less sampling error than simple random sampling with a smaller sample size (Daniel, 2012).

Next, three classes of Year Four pupils (with 115 pupils) and their mathematics teachers were randomly selected. The three teachers were of the same gender and had almost similar years of teaching experience. Knowledgeable outside observers of this study consisted of the Head of the Mathematics Committee, one Excellent Mathematics teacher, and one School Improvement Specialist Coaches (SISC+). The CLR group designed the three lesson plans for teaching perimeter based on the CPA approach, which focused on squares, rectangles, and triangles, respectively. The learning standards for perimeter are to determine the perimeter of squares, rectangles, and triangles. The time taken to 
carry out the teaching and learning process based on the lesson plans was 60 minutes each.

\section{Research Instrument}

Proficiency Test in Perimeter was used in this study. This test was constructed based on the framework that has been put forward by Kilpatrick et al. (2001). The test consisted of 15 open-ended questions with five questions for measuring proficiency in the perimeter of squares, rectangles, and triangles, respectively, designed based on the five components of the Mathematical Proficiency framework. The five components were conceptual understanding, procedural fluency, strategic competence, adaptive reasoning, and productive disposition. The test was validated by a panel of three Year Four Mathematics teachers with at least ten years of teaching experience. In addition, the test was pilot tested to determine its reliability using Cronbach's Alpha. The value of Cronbach's Alpha obtained was 0.91 for the perimeter of squares, 0.89 for rectangles, and 0.89 for the perimeter of triangles. Thus, the test was reliable for the actual study. The Cronbach's Alpha value is a statistical standard for assessing scale reliability and internal consistency by examining internal relationships between items. An alpha value of 0.700 or more generally indicates reliability (Creswell, 2005).

\section{Data Analysis}

The paired-samples t-test was used to determine whether there was a significant difference in proficiency in perimeter between pre-and post-test scores of pupils in Group One, Group Two, and Group Three. In addition, the one-way ANOVA test was used to determine whether there was a significant difference among the three groups. The Statistical Package for the Social Sciences (SPSS) software version 24.0 was used to analyze the data.

\section{RESULTS}

Table 2 shows the mean (M) and standard deviation (SD) difference between pre-and post-test scores for the perimeter of squares, rectangles, and triangles by CLR cycle.

The mean difference between the preand post-test scores for the perimeter of squares, rectangles, and triangles showed an increasing trend from the first cycle to the second cycle and from the second cycle to the third cycle, that is from 3.00 to 3.77 and from 3.77 to 5.16 for the perimeter of

Table 2

Mean and standard deviation difference of pre- and post-test scores for perimeter of squares, rectangles, and triangles by CLR cycle

\begin{tabular}{lcccccc}
\hline \multirow{2}{*}{ Cycles / Results } & \multicolumn{2}{c}{ Squares } & \multicolumn{2}{c}{ Rectangles } & \multicolumn{2}{c}{ Triangles } \\
\cline { 2 - 6 } & $\mathrm{M}$ & $\mathrm{SD}$ & $\mathrm{M}$ & $\mathrm{SD}$ & $\mathrm{M}$ & $\mathrm{SD}$ \\
\hline First Cycle & 3.00 & 0.19 & 3.56 & 0.21 & 1.72 & 0.62 \\
Second Cycle & 3.77 & 0.27 & 3.79 & 0.63 & 3.24 & 0.82 \\
Third Cycle & 5.16 & 1.29 & 4.40 & 0.69 & 7.03 & 1.01 \\
\hline
\end{tabular}


squares, from 3.56 to 3.79 and from 3.79 to 4.40 for the perimeter of squares and from 1.72 to 3.24 and from 3.24 to 7.03 for the perimeter of triangles, respectively.

\section{Paired-Samples t-Tests}

Table 3 shows the results of the pairedsamples t-test for the first, second, and third cycle of CLR for the proficiency in the perimeter of squares, rectangles, and triangles. The results indicated a significant difference between the pre-and post-test mean scores for the first cycle of CLR, the second cycle of CLR, and the third cycle of CLR with $p<.05$. In addition, the results of the paired-samples t-tests for the three CLR cycles for the proficiency in the perimeter of squares, rectangles, and triangles indicated that there was a significant difference between the pre-and post-test mean scores for each CLR cycle with the post-test mean scores higher than the pre-test mean scores in all the three cycles.

\section{One-Way Analysis of Variance (ANOVA) Test}

Table 4 shows the results of the one-way ANOVA test for the first, second, and third cycles of CLR for proficiency in perimeter of squares, rectangles, and triangles. The

Table 3

Paired-samples t-test for the perimeter of squares, rectangles, and triangles for the first, second, and third cycle of CLR

\begin{tabular}{lccccccccc}
\hline \multirow{2}{*}{ Cycles / Results } & \multicolumn{2}{c}{ Squares } & \multicolumn{4}{c}{ Rectangles } & \multicolumn{5}{c}{ Triangles } \\
\cline { 2 - 8 } & $\mathrm{t}$ & df & Sig. (2-tailed) & $\mathrm{t}$ & $\mathrm{df}$ & Sig. (2-tailed) & $\mathrm{t}$ & df & Sig. (2-tailed) \\
\hline $\begin{array}{l}\text { First Cycle } \\
\text { (pretest-posttest) }\end{array}$ & -8.68 & 37 & 0.00 & -13.61 & 38 & 0.00 & -3.92 & 37 & 0.00 \\
$\begin{array}{l}\text { Second Cycle } \\
\text { (pretest-posttest) }\end{array}$ & -11.89 & 38 & 0.00 & -12.74 & 37 & 0.00 & -8.56 & 37 & 0.00 \\
$\begin{array}{l}\text { Third Cycle } \\
\text { (pretest-posttest) }\end{array}$ & -10.83 & 37 & 0.00 & -11.62 & 37 & 0.00 & -20.33 & 38 & 0.00 \\
\hline
\end{tabular}

Table 4

One-way ANOVA tests for first, second, and third cycles of CLR for perimeter of squares, rectangles, and triangles

\begin{tabular}{llccccc}
\hline \multirow{5}{*}{ Squares } & Sum of Squares & df & Mean Square & F & Sig. \\
& Between Groups & 139.64 & 2 & 69.82 & 17.17 & 0.00 \\
& Within Groups & 455.41 & 112 & 4.07 & & \\
Rectangles & Total & 595.04 & 114 & & & \\
& Between Groups & 278.35 & 2 & 139.55 & 19.54 & 0.00 \\
& Within Groups & 301.88 & 112 & 4.07 & & \\
\multirow{5}{*}{ Triangles } & Total & 7464.00 & 114 & & & \\
& Between Groups & 712.34 & 2 & 356.17 & 91.37 & 0.00 \\
& Within Groups & 436.58 & 112 & 3.90 & & \\
& Total & 1148.92 & 114 & & & \\
\hline
\end{tabular}


results indicated a significant difference in the proficiency in the perimeter of squares rectangles, and triangles among the three cycles of CLR with $\mathrm{p}<.05$.

Results for the Shapiro-Wilk Normality Test and the Levene's Test indicated that the post-test scores of the proficiency in the perimeter of squares, rectangles and triangles for the first, second, and third cycles of CLR were normally distributed for each cycle and were assumed to have the same variance because $\mathrm{p}>.05$.

Results for the Tukey Post Hoc also indicated that there was a significant difference in the proficiency in the perimeter of squares, rectangles, and triangles between the first, and the second cycles, the first and the third cycles, and the second and the third cycles of CLR as well at the significance level of .05 .

\section{DISCUSSION}

The first step of the CPA approach began with the concrete step, followed by the pictorial step for improving the pupils' conceptual understanding and procedural fluency and ended with the abstract step for improving the pupils' strategic competence, adaptive reasoning, and productive disposition. The activities available in each step consisted of individual activities and group activities. The CLR members designed the lesson plans for the first cycle of CLR. Group One learned the perimeter of squares in the first cycle, followed by Group Two in the second cycle, and Group Three in the third cycle of the CLR. Then, Group Two learned the perimeter of rectangles in the first cycle, followed by Group Three in the second cycle, and Group One in the third cycle of the CLR. Finally, Group Three learned the perimeter of triangles in the first cycle, Group One in the second cycle, and Group Two in the third cycle of the CLR.

The lesson plan for the third cycle of the CLR would have gone through two revisions: firstly, after the first cycle, and secondly, after the second cycle of the CLR. The first revision would be based on the actual teaching and observation in the classroom in the first cycle of the CLR. The second revision would be based on the actual teaching and observation in the classroom in the second cycle of the CLR. In addition, knowledgeable outside observers consisting of the Head of the Mathematics Committee, Excellent Mathematics teacher, and School Improvement Specialist Coaches Plus (SISC + ) were involved in each revision of the lesson plans by providing their comments and suggestions for the improvement of the lesson plans.

It was supported by the results of the paired-samples t-tests for the three CLR cycles for the proficiency in the perimeter of squares, rectangles, and triangles which indicated that there was a significant difference between the pre-and post-test mean scores for each CLR cycle with the post-test mean scores higher than the pretest mean scores in all the three cycles. In addition, a comparison of the mean difference between the pre-and post-test scores for the proficiency in the perimeter of squares showed that Group Three obtained the highest mean difference $(\mathrm{M}=5.19$, SD $=1.29$ ) because Group Three learned the 
perimeter of squares in the third cycle of the CLR while Group One obtained the lowest mean difference $(\mathrm{M}=3.00$, SD $=0.19$ ) because Group One learned the perimeter of squares in the first cycle of the CLR. Likewise, a comparison of the mean difference between the pre-and post-test scores for the proficiency in the perimeter of rectangles showed that Group One obtained the highest mean difference $(\mathrm{M}=4.40$, SD $=0.69$ ) because Group One learned the perimeter of rectangles in the third cycle of the CLR while Group Two obtained the lowest mean difference $(\mathrm{M}=3.56, \mathrm{SD}$ $=0.21$ ) because Group Two learned the perimeter of rectangles in the first cycle of the CLR. Similarly, comparing the mean difference between the pre-and post-test scores for the proficiency in the perimeter of triangles showed that Group Two obtained the highest mean difference $(\mathrm{M}=7.03, \mathrm{SD}$ $=1.01$ ) because Group Two learned the perimeter of triangles in the third cycle of the CLR. In contrast, Group Three obtained the lowest mean difference $(\mathrm{M}=1.72$, SD $=0.62$ ) because Group Three learned the perimeter of triangles in the first cycle of the CLR.

It was also supported by the results of the one-way ANOVA tests for the first, second, and third cycles of CLR for proficiency in the perimeter of squares, rectangles, and triangles which indicated that there was a significant difference in the proficiency in the perimeter of squares, rectangles and triangles among the three cycles of CLR, respectively. In addition, the Tukey Post Hoc tests indicated that there was a significant difference in the proficiency in the perimeter of squares, rectangles, and triangles between the first and the second cycles, the first and the third cycles, and the second and the third cycles of CLR as well at the significance level of 0.05 . The results indicated that the lesson plan for the third cycle of the CLR produced the highest post-test mean score for proficiency in the perimeter of squares, rectangles, and triangles, respectively.

The results of this study are in agreement with the positive results of various past studies involving Lesson Study (e.g., Aini \& Zanaton, 2018; Akiba et al., 2019; Lim et al., 2018) in Malaysia and other countries to strengthen the professionalism of teachers and educators from various levels. The results of the study also concurred with the positive results of past studies on the CPA (or CRA) approach (e.g., Bouck et al., 2018; Flores, 2018; Flores \& Hinton, 2019; Flores et al., 2019; Hinton \& Flores, 2019; Isip, 2018; Purwadi et al., 2019; Salingay \& Tan, 2018). CLR is a new approach to distinguish it from Lesson Study and was introduced by Takahashi and McDougal (2016). Although no study has ever been done using CLR and CPA approach in Malaysia, the findings of this study supported the hypothesis that the lesson plan for the third cycle of the CLR would produce the highest post-test mean score for proficiency in the perimeter of squares, rectangles, and triangles, respectively.

\section{CONCLUSIONS}

In conclusion, CLR played an important role in ensuring that the CPA approach could be implemented in each study cycle. The 
benefits obtained through CLR in this study are as follows: (a) Teachers are actively involved in each CLR cycle. Therefore, teachers can provide insights before, during, and after the actual teaching was conducted. These activities would increase teachers' confidence; (b) Provide opportunities for teachers to observe the teaching and learning process as it happened in the real classroom. Based on the situation in the classroom, teachers would focus on discussions related to the methods of planning, implementation, and observation. Teachers could also develop an understanding of the concepts and skills that pupils should acquire, and (c) Teachers can find out whether the activities and materials provided such as exercises, textbooks, and activity books were appropriate or not in giving maximum benefits to the pupils. Further, each CLR cycle involved six important steps. The first step was to state a clear purpose: to solve the problems teachers face in improving the teaching and learning of perimeter and to solve the problems pupils face, such as understanding the concepts of the perimeter of squares, rectangles, and triangles. Next, the CLR group would carry out a literature review on the problems that have been identified in the first step.

The literature review covered past studies related to perimeter problems at the school, district, and state levels, and larger studies involving a larger sample at the university and national levels. The third step was the proposed lesson plan by the CLR group, and the revisions made after each CLR cycle based on the observations in the classroom, discussions among members of the CLR group before, during, and after the lesson plan was implemented in the classroom as well as the comments and suggestions from the knowledgeable outside observers. When revisions were made, various aspects were considered, especially involving the pupils' responses in the classroom based on the activities, teaching methods, and constraints encountered during the teaching and learning process. The fourth step was the actual teaching in the classroom, along with a discussion based on its implementation in the classroom. Knowledgeable outside observers were present in each CLR cycle to ensure that the learning objectives could be achieved. The final step of sharing the results was the presentation of the final findings based on the results of the proficiency test in perimeter and observations by the CLR group.

\section{ACKNOWLEDGEMENT}

Acknowledgment to "Ministry of Higher Education for Fundamental Research Grant Scheme with Project Code: FRGS/1/2019/ SS109/USM/02/13".

\section{REFERENCES}

Aini, H. A., \& Zanaton I. (2018). Lesson study: An approach to increase the competency of out-of-field mathematics teacher in building the students conceptual understanding in learning mathematics. Journal of Educational Sciences, 2(2), 1-13. https://doi.org/10.31258/ jes.2.2.p.1-13

Akiba, M., Murata, A., Howard, C. C., \& Wilkinson, B. (2019). Lesson study design features for 
supporting collaborative teacher learning. Teaching and Teacher Education, 77, 352-365.

Bouck, E. C., Satsangi, R., \& Park, J. (2018). The concrete-representational-abstract approach for students with disabilities: An evidencebased practice synthesis. Remedial and Special Education, 39(4), 211-228. https://doi. org/10.1177/ 0741932517721712

Bruner, J. S. (1964). The course of cognitive growth. American Psychologist, 19(1), 1-15.

Bruner, J. S. (1966). Toward a theory of instruction. Harvard University Press.

Creswell, J. W. (2005). Educational research: planning, conducting, and evaluating quantitative and qualitative research ( $2 \mathrm{nd} \mathrm{ed}$.). Pearson Education.

Danielson, C. (2005). Perimeter in the curriculum. For the Learning of Mathematics, 25(1), 30-33.

Daniel, J. (2012). Sampling essentials: Practical guidelines for making sampling choices. SAGE Publications, Inc. https:// doi. org/10.4135/9781452272047

Fernandez, C., \& Yoshida, M. (2004). Lesson study: A Japanese approach to improving

Mathematics teaching and learning. Lawrence Erlbaum Associates.

Flores, M. M. (2018). Making mathematics accessible for elementary students who struggle: Using CRA/CSA for interventions. Plural Publishing.

Flores, M. M., \& Hinton, V. M. (2019). Improvement in elementary students' multiplication skills and understanding after learning through the combination of the concrete representationalabstract sequence and strategic instruction. Education and Treatment of Children, 42(1), 73-100.

Flores, M. M., Kaffar, B. J., \& Hinton, V. (2019). A comparison of the effectiveness of using CRASIM vs. direct instruction to teach multiplication with regrouping. International Journal for Research in Learning Disabilities, 4(1), 27-40.

Gay, L. R., Mills, G. E., \& Airasian, P. W. (2011). Educational research: Competencies for analysis and applications (10th ed.). Pearson Education International.

Hinton, V. M., \& Flores, M. M. (2019). The effects of the concrete-representational-abstract sequence for students at risk for mathematics failure. Journal of Behavioral Education, 28, 493-516. https://doi.org/10.1007/s10864-018-09316-3

Isip, J. L. (2018). Comparison between traditional approach and concrete-pictorial-abstract (CPA) approach in teaching college algebra. International Journal of Scientific \& Engineering Research, 9(9), 1290-1294.

Kilpatrick, J., Swafford, J., \& Findell, B. (2001). Adding it up: Helping children learn mathematics. National Academy Press.

Lewis, C. (2002). Lesson study: A handbook of teacher-led instructional change. Research for Better Schools, Inc.

Lim, C. S., The, K. H., \& Chiew, C. M. (2018). Promoting and implementing lesson study in Malaysia: Issue of sustainability. In M. Quaresma, C. Winsløw, S. Clivaz, J. da Ponte, A. Ní Shúilleabháin, \& A. Takahashi (Eds.), Mathematics lesson study around the world. ICME-13 Monographs. Springer, Cham. https:// doi.org/10.1007/978-3-319-75696-7_3

Ma, L. (1999). Knowing and teaching elementary mathematics. Lawrence Erlbaum Associates.

Machaba, F. M. (2016). The concepts of area and perimeter: Insights and misconceptions of Grade 10 learners. Pythagoras, 37(1), 1-11.

National Research Council. (2001). Adding it up: Helping children learn mathematics. In J. Kilpatrick, J. Swafford, \& B. Findell (Eds.), Mathematics Learning Study Committee, Center 
for Education, Division of Behavioral and Social Sciences and Education. National Academy Press.

Purwadi, I. M. A., Sudiarta, I. G. P., \& Suparta, I. N. (2019). The effect of concrete-pictorialabstract strategy toward students' mathematical conceptual understanding and mathematical representation on fractions. International Journal of Instruction, 12(1), 1113-1126. https:// doi.org/10.29333/iji.2019.12171a

Salingay, N. R., \& Tan, D. A. (2018). Concretepictorial-abstract approach on student's attitude and performance in mathematics. International Journal of Scientific \& Technology Research, 7(5), 90-111.

Sutherland, M., Firestone, A. R., Doabler, C. T., \& Clarke, B. (2020). Building conceptual understanding of linear measurement: Teaching students with mathematics learning disabilities. Teaching Exceptional Children, 53(1), 70-78.

Takahashi, A., \& McDougal, T. (2016). Collaborative lesson research: Maximizing the impact of lesson study. ZDM Mathematics Education, 1-14.

Takahashi, A., \& McDougal, T. (2018). Collaborative lesson research (CLR). In M. Quaresma,
C. Winsløw, S. Clivaz, J. da Ponte, A. Ní Shúilleabháin, \& A. Takahashi (Eds.), Mathematics lesson study around the world. ICME-13 Monographs. Springer, Cham. https:// doi.org/10.1007/978-3-319-75696-7_8

Takahashi, A., \& McDougal, T. (2019). Using schoolwide collaborative lesson research to implement standards and improve student learning: Models and preliminary results. In R. Huang, A. Takahashi, \& J. da Ponte (Eds.), Theory and practice of lesson study in mathematics: Advances in mathematics education. Springer, Cham. https://doi.org/10.1007/978-3-03004031-4_14

Van de Walle, J. A., Karp, K. S., \& Bay-Williams, J. M. (2014). Elementary and middle school mathematics: Teaching developmentally. Pearson Education.

Watanabe, T., Takahashi, A., \& Barham, A. I. (2019). Implementing school-wide collaborative lesson research in Qatar. Journal of Institutional Research Southeast Asia, 17(2), 47-70.

Zhang, D. (2021). Teaching geometry to students with learning disabilities: Introduction to the special series. Learning Disability Quarterly, 44(1), 4-10. 
